\title{
Ascorbic acid provides protection for human chondrocytes against oxidative stress
}

\author{
ZHIQIANG CHANG* ${ }^{*}$, LIFENG HUO*, PENGFEI LI, YIMIN WU and PEI ZHANG \\ Department of Cervical Spinal Surgery, The Second Affiliated Hospital of Inner Mongolia Medical University, \\ Hohhot, Mongolia 010030, P.R. China
}

Received August 5, 2014; Accepted July 3, 2015

DOI: $10.3892 / \mathrm{mmr} .2015 .4231$

\begin{abstract}
Oxidative stress is considered to be an important cause of dysfunction in chondrocytes and articular cartilage degradation, which leads to the pathogenesis of osteoarthritis (OA) and cartilage aging. The present study aimed to assess the effects of the widely applied antioxidant, ascorbic acid (AA), on human chondrocytes against hydrogen peroxide $\left(\mathrm{H}_{2} \mathrm{O}_{2}\right)$ in vitro. Using annexin $\mathrm{V}$-fluorescein isothiocyanate, 3-(4,5-dimethylthiazol-2-yl)-2,5-diphenyl tetrazolium bromide and senescence-associated $\beta$-galactosidase assays, the present study identified that AA reduced apoptosis, reduced the loss of viability and markedly decreased $\mathrm{H}_{2} \mathrm{O}_{2}$-mediated senescence in cells treated with $\mathrm{H}_{2} \mathrm{O}_{2}$. Furthermore, AA not only stimulated the expression levels of collagens and proteoglycans, but also inhibited the differentiation of chondrocytes under conditions of oxidative stress. In addition, reverse transcription-quantitative polymerase chain reaction and western blotting demonstrated that AA decreased the activity of nrf2, $\mathrm{NF}-\kappa \mathrm{B}, \mathrm{AP} 1$ and matrix metalloproteinase-3, which is stimulated by $\mathrm{H}_{2} \mathrm{O}_{2}$. In conclusion, AA efficiently protected human chondrocytes against damage induced by $\mathrm{H}_{2} \mathrm{O}_{2}$ by regulating multiple regulatory pathways.
\end{abstract}

\section{Introduction}

Chondrocyte dysfunction results in the cervical spondylosis associated with degeneration of the intervertebral disc, or the joint disorder osteoarthritis (OA), which is characterized by progressive breakdown of articular cartilage (1-3). Chondrocytes are sensitive to environmental and multiple

Correspondence to: Dr Pei Zhang, Department of Cervical Spinal Surgery, The Second Affiliated Hospital of Inner Mongolia Medical University, 1 Yingfang Dao Hohehot, Hohhot, Mongolia 010030, P.R. China

E-mail: zhangpmg@163.com

*Contributed equally

Key words: oxidative stress, ascorbic acid, chondrocytes, apoptosis, senescence cellular stresses, including inflammation, mechanical loading, stress to the endoplasmic reticulum and hypoxia (4-6). Reactive oxygen species (ROS), another major determinant of stress, including hydrogen peroxide $\left(\mathrm{H}_{2} \mathrm{O}_{2}\right)$, hypochlorite ion, hydroxyl radical and superoxide anion, are involved in normal intracellular transduction and degenerative cellular processes. Increased ROS production is considered to be an important cause of chondrocyte dysfunction and articular cartilage degradation, which leads to the pathogenesis of OA and the aging of cartilage (7-10). Chondrocytes and cartilage tissues exhibit efficient protective strategies to minimize damage induced by increased ROS production, including $\mathrm{H}_{2} \mathrm{O}_{2}(7,11)$. Previous studies have investigated various antioxidant supplements, including resveratrol, quercetin, vitamin E, and other strategies (12-15). However, information available on the antioxidative status of chondrocytes is limited (16). Therefore, identifying available and promising antioxidative strategies or antioxidant drugs to combat oxidative stress in chondrocytes is required.

Ascorbic acid (AA) is widely used in clinical applications and is known for its role in bone formation, wound healing and the maintenance of healthy gums. AA is involved in protecting the immune system and combating infection and allergic reactions (17). AA is also regarded as the most important antioxidant, which provides protection against oxidative stress. It has been previously reported that AA may be a potential drug for therapeutic intervention and to slow the progression of age-associated diseases, including atherogenesis and Alzheimer's disease (17,18). Previous studies have revealed that AA attenuates oxidative stress in diabetic aged rats $(19,20)$. AA also exerts a role in chondroprotection: The application of AA and mechanical stimulation in combination was revealed to improve the mechanical characteristics of regenerated cartilage (21). AA was revealed to markedly affect the expression of proteins with specific functions in human articular chondrocytes under conditions of homogentisic acid-induced stress, which may be mediated by protein oxidation (22). A combination of $\alpha$-tocopherol (0.1-2.5 $\mu \mathrm{M})$, AA $(10-50 \mu \mathrm{M})$ and selenium $(1-50 \mathrm{nM})$ provided a promising strategy to combat oxidative stress and cytokine-induced matrix degradation in chondrocytes (23). AA supplementation of chondrocytes following static loading was demonstrated to have the potential to reduce the morphological and biochemical degeneration of chondrocytes in vivo (24). These previous 
findings support the hypothesis that AA may be a promising drug or antioxidant to protect against the chondrocyte damage induced by oxidative stress. However, no reports in this research area currently exist.

The present study focused on the role of AA in combating oxidative stress and the crosstalk between AA and response transcription factors under conditions of oxidative stress in C28/I2 human chondrocytes.

\section{Materials and methods}

Cell culture and cell treatments. The human C28/I2 chondrocyte cell line was acquired from Type Culture Collection of the Chinese Academy of Sciences (Shanghai, China). The cells were cultivated in Dulbecco's modified Eagle's medium (DMEM), containing 10\% fetal bovine serum (Gibco Life Technologies, Carlsbad, CA, USA) and antibiotics (50 U/ml penicillin and $50 \mu \mathrm{g} / \mathrm{ml}$ streptomycin; Invitrogen Life Technologies, Carlsbad, CA, USA), in $5 \% \mathrm{CO}_{2}$ at $37^{\circ} \mathrm{C}$. The cells were subcultured after reaching $\sim 90 \%$ confluence. AA (Sigma-Aldrich, St. Louis, MO, USA) and $\mathrm{H}_{2} \mathrm{O}_{2}$ (Sigma-Aldrich) were diluted in serum-free DMEM. The cells were treated with $\mathrm{H}_{2} \mathrm{O}_{2}(100 \mu \mathrm{M})$ for $4 \mathrm{~h}$ following incubation with AA at 100 (AA100 group) or $200 \mu \mathrm{M}$ (AA200 group) for $24 \mathrm{~h}$ after the C28/I2 cells had reached $80 \%$ confluence. Normal C28/I2 cells without treatment and C28/I2 cells treated with $\mathrm{H}_{2} \mathrm{O}_{2}(100 \mu \mathrm{M})$ were denoted as the $\mathrm{N}$ group and $\mathrm{C}$ group, respectively.

Analysis of apoptosis. The annexin-V-fluorescein isothiocyanate (FITC) apoptosis detection kit was used to analyze apoptosis in the cells, according to the manufacturer's instructions (KeyGen Biotech. Co., Ltd., Nanjing, China). The cells were harvested following the indicated treatments and cell suspensions were fixed overnight with ice-cold $70 \%$ ethanol. The fixed cells were subsequently stained with propidium iodide or annexin V-FITC following centrifugation at $70 \mathrm{xg}$ for $5 \mathrm{~min}$ at room temperature, and resuspension. Analyses were performed using a flow cytometer (BD FACScan; BD Biosciences, Franklin Lakes, NJ, USA). The results were expressed as the percentage of apoptotic cells from the total cells.

3-(4,5-dimethylthiazol-2-yl)-2,5-diphenyl tetrazolium bromide (MTT) assay. Cell viability was determined using an MTT assay (Sigma-Aldrich), following the indicated treatments. Briefly, $50 \mu \mathrm{g} / \mathrm{ml} \mathrm{MTT}$ was added to the cells at $37^{\circ} \mathrm{C}$ for $4 \mathrm{~h}$. Following incubation, the MTT-containing medium was discarded and dimethyl sulfoxide was added to dissolve the formazan crystals. The optical densities (OD) were measured at $490 \mathrm{~nm}$ using a Versamax microplate reader (Molecular Devices, Sunnyvale, CA, USA). The viability of the cells was normalized, according to the OD value/cell number, and the quantity of normal C28/I2 cells was denoted as $100 \%$.

Cell senescence assay. For the senescence-associated $\beta$-galactosidase (SA- $\beta$-gal) assay, cell senescence was measured using a cellular senescence assay kit (Cell Biolabs, San Diego, CA, USA), according to the manufacturer's instructions. Briefly, the cells $\left(5 \times 10^{4}\right)$ were treated as indicated and following treatment, the cells were washed with phosphate-buffered saline (PBS), harvested and collected by centrifugation at $70 \mathrm{x}$ g for $5 \mathrm{~min}$ at room temperature. The cells were treated with freshly prepared fluorimetric substrate for $2 \mathrm{~h}$ at $37^{\circ} \mathrm{C}$ in the dark. The fluorescence intensity of each reaction mixture was determined and quantified using Image J software (NIH, Bethesda, MD, USA). The average fluorescence intensity was analyzed from five fields for each treatment using Image J 1.38.

Reverse transcription-quantitative polymerase chain reaction $(R T-q P C R)$. The total RNA was isolated from the cells using an RNeasy kit (Qiagen, Valencia, CA, USA). RT-qPCR was performed on an Applied Biosystems 7500 instrument with SYBR Green PCR kits (Applied Biosystems, Foster City, CA, USA). First-strand cDNA was synthesized using reverse transcription reagents (PrimeScript ${ }^{\mathrm{TM}}$ RT reagent kit; Takara Biotechnology Co., Ltd., Dalian, China). The reactions were conducted with the following thermocycling conditions: at $95^{\circ} \mathrm{C}$ for $10 \mathrm{~min}$, followed by 45 cycles of $95^{\circ} \mathrm{C}$ for $10 \mathrm{~s}, 56^{\circ} \mathrm{C}$ for $30 \mathrm{~s}$ and extension for $10 \mathrm{~s}$ at $72^{\circ} \mathrm{C}$. The data were assessed using the $2^{-\Delta \Delta \mathrm{Ct}}$ method for relative quantification $(21,22)$. The GAPDH gene was used as the endogenous control for normalization. The primer sequences (synthesized by Sangon Biotech Co., Ltd, Beijing, China) were as follows: Colla1, forward: 5'-CAAGATGGTGGCCGTTACTAC-3' and reverse: 5'-TTAGTCCTTACCGCTCTTCCAG-3'; Col2a1, forward: 5'-GACTTTCCTCCGTCTACTGTCC-3' and reverse: 5'-GTGTACGTGAACCTGCTGTTG-3'; Agc1, forward: 5'-ACTGAAGGACAGGTTCGAGTG-3' and reverse: 5'-CACACCGATAGATCCCAGAGT-3'; Nrf2, forward: 5'-TTCAAAGCGTCCGAACTCCA-3' and reverse: 5'-AATGTCTGCGCCAAAAGCTG-3'; matrix metalloproteinase-3 (MMP-3), forward: 5'-CTGGACTCCGACACTCTG GA-3' and reverse: 5'-CAGGAAAGGTTCTGAAGTGACC-3'; AP1, forward: 5'-TGTCTGTGGCTTCCCTTGATCTGA-3' and reverse: 5'-TGGATGATGCTGGGAACAGGAAGT-3'; GAPDH, forward: 5'-GCACCGTCAAGGCTGAGAAC-3'; reverse: 5'-ATGGTGGTGAAGACGCCAGT-3'.

Nuclear fraction preparation. The nuclear and cytosolic fractions were separated using a Nuclear and Cytoplasmic Protein Extraction kit obtained from the Beyotime Institute of Biotechnology (Jiangsu, China). The cell pellets were resuspended in $100 \mu \mathrm{l}$ cytosolic extract A reagent, containing $1 \mathrm{mM}$ PMSF and vortexed for $5 \mathrm{sec}$. Subsequently, $5 \mu \mathrm{l}$ cytosolic extract $B$ reagent was added to the lysates and the samples were vortexed for $5 \mathrm{sec}$. The supernatant (cytosolic fractions) was acquired following centrifugation at $13,000 \mathrm{x}$ g at $4^{\circ} \mathrm{C}$ for 5 min, after which the pellets were resuspended in $30 \mu \mathrm{l}$ nuclear extract reagent, containing $1 \mathrm{mM}$ PMSF, and centrifuged again at $13,000 \mathrm{x} \mathrm{g}$ at $4^{\circ} \mathrm{C}$ for $10 \mathrm{~min}$. The resulting supernatants (nuclear fraction) were extracted and subsequently analyzed to assess the protein expression of nrf 2 in the nuclear fraction.

Immunoblotting. Western blotting was performed using a standard procedure, as described previously (6). Briefly, the C28/I2 chondrocytes were lysed using a lysis reagent (Promega Corporation, Madison, WI, USA) and the proteins were fractionated on $10 \%$ SDS-PAGE gels (Sigma-Aldrich) and 
A

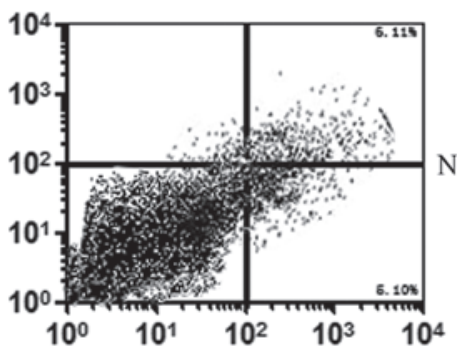

C

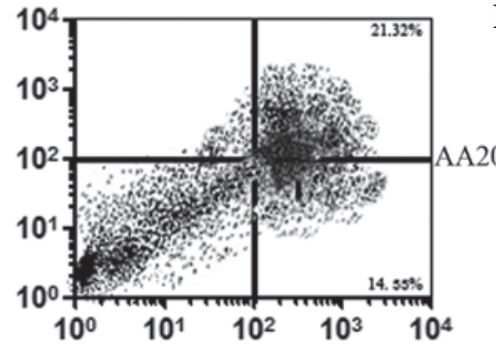

B

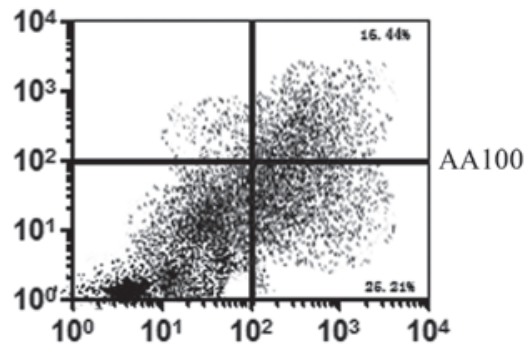

D

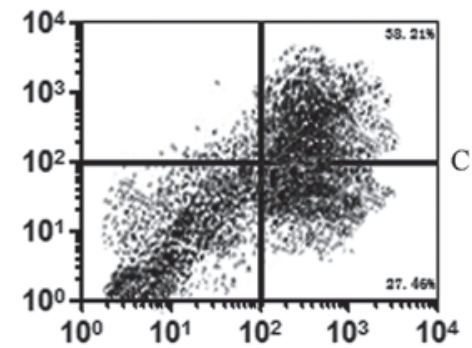

$\mathbf{E}$

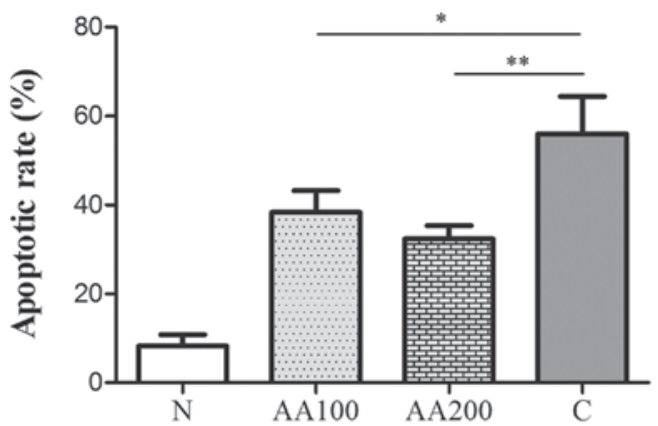

Figure 1. Effect of AA on the apoptosis of C28/I2 cells in the presence of $\mathrm{H}_{2} \mathrm{O}_{2}$. The C28/I2 cells were preincubated with 100 or $200 \mu$ M AA (AA100 and AA200, respectively) for $24 \mathrm{~h}$. The cells were subsequently treated with $\mathrm{H}_{2} \mathrm{O}_{2}$ for $4 \mathrm{~h}$. (A-D) Apoptosis was measured using an annexin V-fluorescein isothiocyanate assay All experiments were performed in triplicate. (E) The data were normalized and expressed as the mean \pm standard deviation. Significant differences are denoted as "P $<0.05$ and ${ }^{* *} \mathrm{P}<0.01$. AA, ascorbic acid; $\mathrm{N}$, normal C28/I2 cells; $\mathrm{C}$, cells treated with $100 \mu \mathrm{M} \mathrm{H}_{2} \mathrm{O}_{2}$ for $4 \mathrm{~h}$; AA100, cells preincubated with $100 \mu \mathrm{M}$ AA for $24 \mathrm{~h}$ and treated with $100 \mu \mathrm{M} \mathrm{H}_{2} \mathrm{O}_{2}$ for $4 \mathrm{~h}$; AA200, cells preincubated with $200 \mu \mathrm{M}$ AA for $24 \mathrm{~h}$ and treated with $100 \mu \mathrm{M} \mathrm{H}_{2} \mathrm{O}_{2}$ for $4 \mathrm{~h}$.

electrotransferred onto nitrocellulose membranes (Millipore, Billerica, MA, USA). The membranes were incubated with primary antibodies for $2 \mathrm{~h}$ at $37^{\circ} \mathrm{C}$ and then blocked with PBS containing $1 \%$ bovine serum albumin and $0.02 \%$ Tween 20 (Sigma-Aldrich). The signals were acquired using an enhanced chemiluminescence detection system (SuperSignal West Femto; Pierce Biotechnology, Inc., Rockford, IL, USA) following incubation with horseradish-peroxidase-conjugated goat anti-rabbit immunoglobulin $\mathrm{G}$ secondary antibody (1:500; cat. no. G-21079; Pierce Biotechnology, Inc.). The primary antibodies used in the present study were as follows: Rabbit monoclonal anti-NF-кB (1:500; cat. no. 8242; Cell Signaling Technology, Inc., Beverly, MA, USA), rabbit phosphorylated (p)-STAT3 (Tyr705; 1:500; p-NF-кB; cat. no. 3033; Cell Signaling Technology, Inc.), rabbit monoclonal anti-nrf2 (1:500; cat. no. SAB4501984; Sigma-Aldrich) and rabbit anti- $\beta$-actin antibody (1:1,000; cat. no. A2066; Sigma-Aldrich).

Statistical analysis. All experiments were performed, at least, in triplicate. All the data were expressed as the mean \pm standard deviation or as the mean \pm standard error. The PASW Statistics 18 software package (formerly SPSS Statistics) was used for statistical analysis (SPSS, Inc., Chicago, IL, USA). Comparison among multiple samples was performed by
A

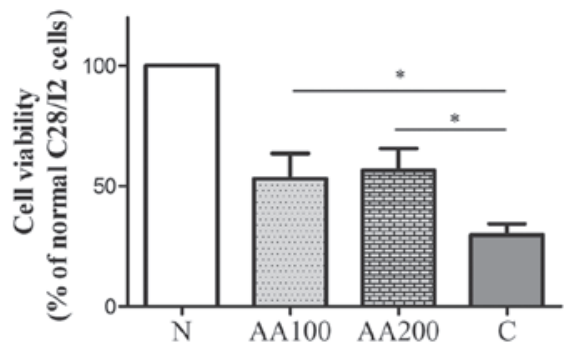

B

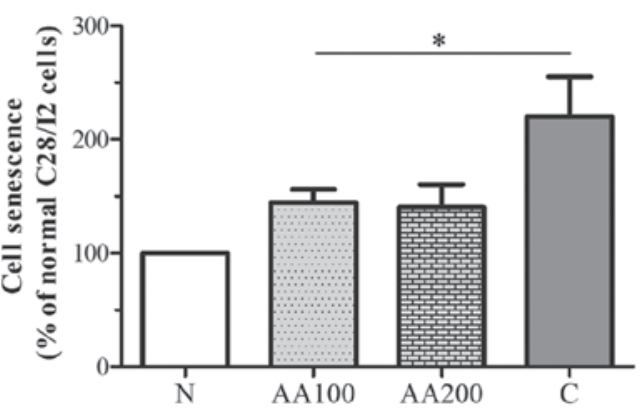

Figure 2. Measurement of cell viability and senescence. (A) Cell viability and (B) senescence were measured using MTT and $\beta$-gal assays, respectively. The data are presented as the mean \pm standard deviation. Significant differences are denoted as ${ }^{*} \mathrm{P}<0.05$. N, normal C28/I2 cells; C, cells treated with $100 \mu \mathrm{M} \mathrm{H}_{2} \mathrm{O}_{2}$ for $4 \mathrm{~h}$; AA100, cells preincubated with $100 \mu \mathrm{M}$ AA for $24 \mathrm{~h}$ and treated with $100 \mu \mathrm{M} \mathrm{H}_{2} \mathrm{O}_{2}$ for $4 \mathrm{~h}$; AA200, cells preincubated with $200 \mu \mathrm{M}$ AA for $24 \mathrm{~h}$ and treated with $100 \mu \mathrm{M} \mathrm{H}_{2} \mathrm{O}_{2}$ for $4 \mathrm{~h}$. 
one-way analysis of variance and Student's t-test was used to compare two groups. $\mathrm{P}<0.05$ was considered to indicate a statistically significant difference.

\section{Results}

AAreduces $\mathrm{H}_{2} \mathrm{O}_{2}$-mediated apoptosis. The C28/I2 human chondrocytes were treated with $\mathrm{H}_{2} \mathrm{O}_{2}$ to simulate pathophysiological oxidative stress as it occurs in vivo. The treatment groups were as follows: $\mathrm{N}$ group, normal C28/I2 cells; $\mathrm{C}$ group, cells treated with $100 \mu \mathrm{M} \mathrm{H}_{2} \mathrm{O}_{2}$ for $4 \mathrm{~h}$; AA100 group, cells preincubated with $100 \mu \mathrm{M}$ AA for $24 \mathrm{~h}$ and treated with $100 \mu \mathrm{M} \mathrm{H}_{2} \mathrm{O}_{2}$ for $4 \mathrm{~h}$; AA200 group, cells preincubated with $200 \mu \mathrm{M}$ AA for $24 \mathrm{~h}$ and treated with $100 \mu \mathrm{M} \mathrm{H}_{2} \mathrm{O}_{2}$ for $4 \mathrm{~h}$. It was revealed that $\mathrm{H}_{2} \mathrm{O}_{2}$ significantly increased the levels of apoptosis when compared with the normal cells ( $\mathrm{N}$ group, $\mathrm{P}<0.001$ ), as shown in Fig. 1. notably, preincubation with $100 \mu \mathrm{M}$ AA resulted in a significant decrease in the levels of apoptosis compared with the $\mathrm{C}$ group $(\mathrm{P}=0.034)$. An increased concentration of $\mathrm{AA}$ $(200 \mu \mathrm{M})$ led to a modest decrease in the levels of apoptosis compared with the AA100 group. Significant differences in the levels of apoptosis between the AA groups and the $\mathrm{N}$ group were observed $(\mathrm{P}<0.001)$. These data suggested that AA markedly reduced $\mathrm{H}_{2} \mathrm{O}_{2}$-mediated apoptosis, however, preincubation with AA (100 and $200 \mu \mathrm{M})$ failed to completely abolish the effects of $\mathrm{H}_{2} \mathrm{O}_{2}$ on cellular apoptosis.

AA protects chondrocytes from $\mathrm{H}_{2} \mathrm{O}_{2}$-induced loss of viability and senescence. Cell viability and senescence are characterized by a loss of function and integrity, which contribute to the progressive degeneration of tissues $(25,26)$. The cell viability and senescence of chondrocytes were determined under oxidative stress conditions mediated by $\mathrm{H}_{2} \mathrm{O}_{2}$ or AA pretreatment using an MTT assay or the SA- $\beta$-gal assay, as shown in Fig. 2. Incubation with $\mathrm{H}_{2} \mathrm{O}_{2}$ stimulated a loss in cell viability and promoted the senescence-like phenotype of chondrocytes when compared with the normal $\mathrm{C} 28 / \mathrm{I} 2$ cells $(\mathrm{P}<0.001)$. Addition of $100 \mu \mathrm{M}$ AA significantly reduced the loss of viability $(\mathrm{P}=0.023)$ and good agreement was obtained with the SA- $\beta$-gal activity assay used to measure senescence induced by $\mathrm{H}_{2} \mathrm{O}_{2}(\mathrm{P}=0.026)$ compared with the $\mathrm{C}$ group. Following treatment with a higher concentration of AA $(200 \mu \mathrm{M})$, the effects of AA were further enhanced (AA200 group vs. AA100 group, $56.48 \pm 9.17$ vs. $53.17 \pm 10.40 \%$ with the MTT assay and $130.33 \pm 10.69$ vs. $144.71 \pm 11.39 \%$ with the SA- $\beta$-gal assay; Fig. 2). These results clearly revealed that AA significantly protected chondrocytes from a loss of viability and from senescence induced by $\mathrm{H}_{2} \mathrm{O}_{2}$.

AA affects the differentiation and expression of proteoglycans and collagens in human chondrocytes exposed to $\mathrm{H}_{2} \mathrm{O}_{2}$ To investigate the role of AA in the expression and differentiation of collagens and proteoglycans in chondrocytes when exposed to oxidative stress, the expression levels of the major factors, Col1a1, Col2a1 and Agc1, were detected by RT-qPCR, as shown in Fig. 3A-C. Oxidative stress not only suppressed the expression levels of Col2a1 and Agc1 $(\mathrm{P}<0.001)$, but also increased the expression of Colla1 $(\mathrm{P}<0.001)$ compared with the normal cells ( $\mathrm{N}$ group). Preincubation with AA resulted in a significant increase in the relative expression

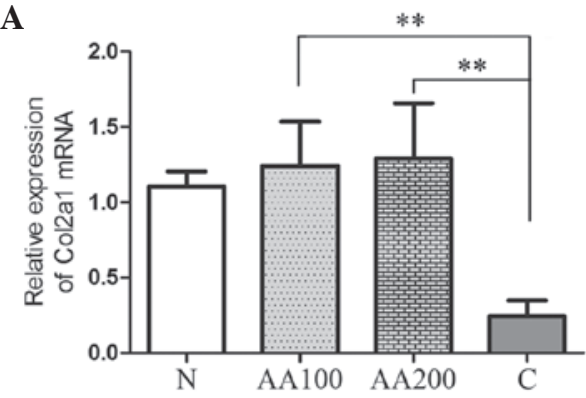

B

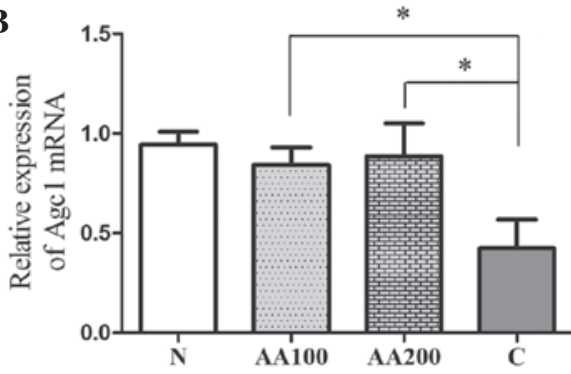

C

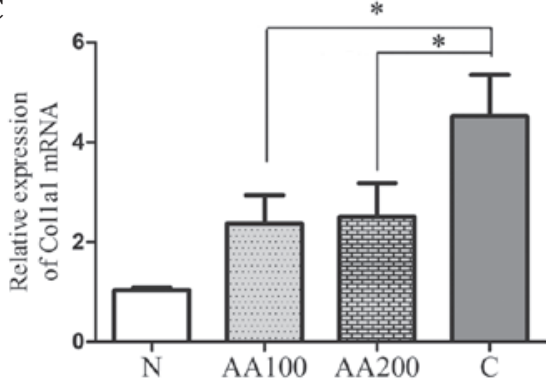

D

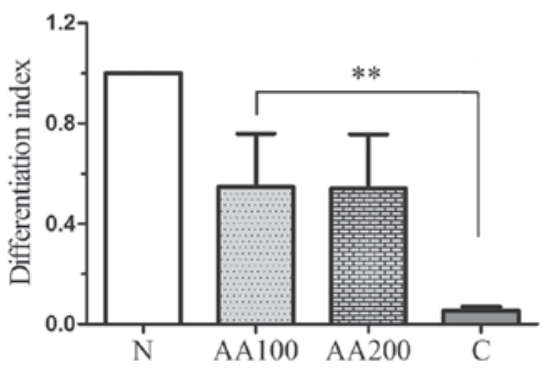

Figure 3. AA affects the expression of genes associated with proteoglycans, collagens and differentiation in the C28/I2 cells exposed to $\mathrm{H}_{2} \mathrm{O}_{2}$. Reverse transcription-quantitative polymerase chain reaction was performed to assess the mRNA expression levels of (A) Col2a1, (B) Agc1 and (C) Col1a1 in the N, AA100, AA200 and C groups. (D) Differentiation indexes were defined as the ratio between the mRNA expression levels of Col2a1 and Colla1. The $2^{-\Delta \Delta C t}$ method was used for relative quantification and the data from three individual experiments were normalized, and statistically analyzed by analysis of variance. Significant differences were denoted as ${ }^{*} \mathrm{P}<0.05$ and ${ }^{* * *} \mathrm{P}<0.01$. N, normal $\mathrm{C} 28 / \mathrm{I} 2$ cells; $\mathrm{C}$, cells treated with $100 \mu \mathrm{M} \mathrm{H}_{2} \mathrm{O}_{2}$ for $4 \mathrm{~h}$; AA100, cells preincubated with $100 \mu \mathrm{M} \mathrm{AA}$ for $24 \mathrm{~h}$ and treated with $100 \mu \mathrm{M} \mathrm{H}_{2} \mathrm{O}_{2}$ for $4 \mathrm{~h}$; AA200, cells preincubated with $200 \mu \mathrm{M}$ AA for $24 \mathrm{~h}$ and treated with $100 \mu \mathrm{M} \mathrm{H}_{2} \mathrm{O}_{2}$ for $4 \mathrm{~h}$.

levels of Col2a1 (AA100, $\mathrm{P}=0.005 ; \mathrm{AA} 200, \mathrm{P}<0.001)$ and Agcl (AA100, $\mathrm{P}=0.013$; AA200, $\mathrm{P}=0.022$ ), and significantly decreased the expression of Col1al (AA100, $\mathrm{P}=0.015$; AA200, $\mathrm{P}=0.031)$ compared with the $\mathrm{C}$ group. The differentiation index (Fig. 3D) was calculated as the ratio of the expression levels between Col2al and Collal (27). Addition of $\mathrm{H}_{2} \mathrm{O}_{2}$ decreased the differentiation index, whereas preincubation with AA 
A

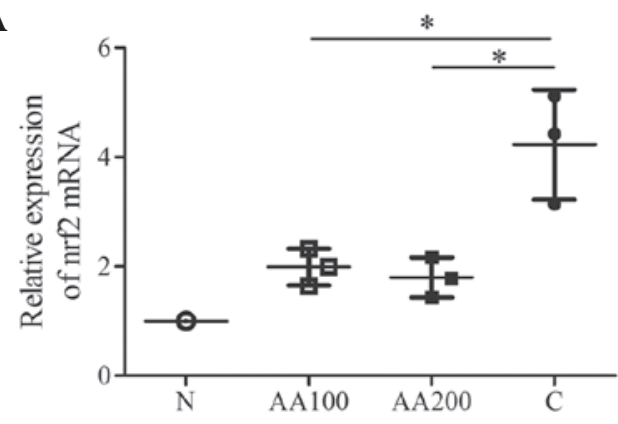

C

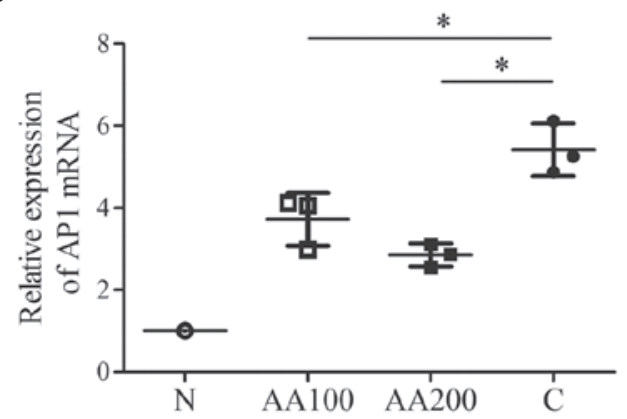

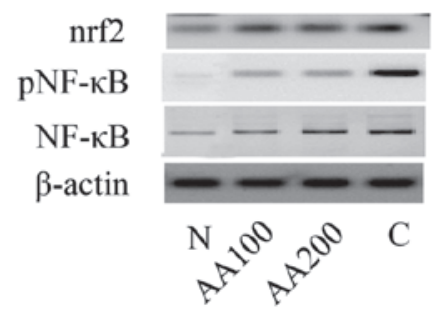

D

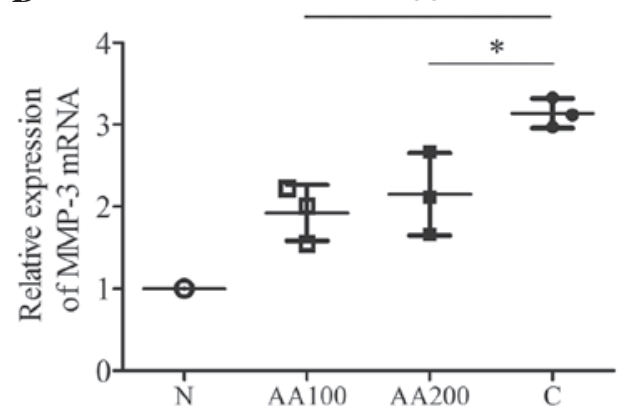

Figure 4. AA altered the expression levels of multiple transcription factors in C28/I2 cells under conditions of oxidative stress. The C28/I2 cells were treated accordingly and the expression of nrf 2 was determined by (A) RT-qPCR and (B) western blotting. The total protein expression levels of NF- $\kappa$ B and pNF- $\kappa$ B were also measured by western blotting. $\beta$-actin was used as an endogenous control. The (C) AP1 and (D) MMP-3 genes were detected by RT-qPCR. The 2 - $\Delta \Delta \mathrm{C}$ method was used for relative quantification of the data and the data from three individual experiments were normalized, and statistically analyzed by analysis of variance. Significant differences were denoted as ${ }^{*} \mathrm{P}<0.05$ and ${ }^{* *} \mathrm{P}<0.01$. RT-qPCR, reverse transcription-quantitative polymerase chain reaction; $\mathrm{p}$, phosphorylated; N, normal C28/I2 cells; C, cells treated with $100 \mu \mathrm{M} \mathrm{H}_{2} \mathrm{O}_{2}$ for $4 \mathrm{~h}$; AA100, cells preincubated with $100 \mu \mathrm{M}$ AA for $24 \mathrm{~h}$ and treated with $100 \mu \mathrm{M}$ $\mathrm{H}_{2} \mathrm{O}_{2}$ for $4 \mathrm{~h}$; AA200, cells preincubated with $200 \mu \mathrm{M}$ AA for $24 \mathrm{~h}$ and treated with $100 \mu \mathrm{M} \mathrm{H}_{2} \mathrm{O}_{2}$ for $4 \mathrm{~h}$.

increased the differentiation index (Fig. 3D). These findings revealed that AA not only stimulated the expression of collagens and proteoglycans, but also inhibited the differentiation of chondrocytes in the presence of oxidative stress.

AA contributes to the inhibition of multiple transcription factors in $\mathrm{C} 28 / \mathrm{I} 2$ cells exposed to $\mathrm{H}_{2} \mathrm{O}_{2}$. In order to assess transcription factor(s), which are modulated by AA, certain known stress and toxicity responding factors ( $\mathrm{nrf} 2, \mathrm{NF}-\kappa \mathrm{B}, \mathrm{AP} 1$ and MMP-3) found in four different signaling pathways were investigated. $\mathrm{H}_{2} \mathrm{O}_{2}$ markedly upregulated the mRNA expression levels of nrf2, AP1 and MMP-3 ( $\mathrm{P}<0.001)$, in addition to stimulating the activation of $\mathrm{NF}-\kappa \mathrm{B}$ when compared with the $\mathrm{N}$ group (Fig. 4). Preincubation with $100 \mu \mathrm{M}$ AA attenuated the increase in the expression of $\operatorname{nrf} 2(\mathrm{P}=0.022)$ and the protein expression of nrf2 induced by $\mathrm{H}_{2} \mathrm{O}_{2}$ (Figs. $4 \mathrm{~A}$ and B). Furthermore, $100 \mu \mathrm{M} \mathrm{AA}$ decreased the activation of $\mathrm{NF}-\kappa \mathrm{B}$ compared with the $\mathrm{C}$ group (Fig. 4B). In addition, $100 \mu \mathrm{M}$ AA decreased the mRNA expression levels of AP1 $(\mathrm{P}=0.032)$ and MMP-3 $(\mathrm{P}=0.006)$ compared with the $\mathrm{C}$ group (Figs. $4 \mathrm{C}$ and D). A higher concentration of $\mathrm{AA}$ $(200 \mu \mathrm{M})$ elicited similar effects on the mRNA expression levels of the three transcription factors (nrf2, $\mathrm{P}=0.017$; AP1, $\mathrm{P}=0.045$; MMP-3, $\mathrm{P}=0.033$ ) and on the activation of $\mathrm{NF}-\kappa \mathrm{B}$ (Fig. 4). These data suggested that $\mathrm{AA}$ may protect human chondrocytes from injuries induced by $\mathrm{H}_{2} \mathrm{O}_{2}$ by exerting regulatory roles in the antioxidant response via the protein kinase $\mathrm{C}(\mathrm{PKC}) / \mathrm{nrf} 2$, $\mathrm{NF}-\kappa \mathrm{B}$ and c-Jun N-terminal kinase (JNK)/AP1 signaling pathways, and in the inflammatory process. In other words, the effects of AA may be mediated via multiple regulatory pathways in C28/I2 cells when exposed to oxidative stress.

\section{Discussion}

Oxidative stress is regarded as a major cause of the degradation of chondrocytes and articular cartilage, which results in the pathogenesis of OA and the aging of cartilage $(9,10,16)$. Several previous reports have focussed on the various strategies used to resist oxidative stress $(14,28)$. Exploiting antioxidant treatment has been demonstrated as a promising strategy for the protection of chondrocytes against oxidative stress. Antioxidants were identified to exert cytoprotective effects in vitro and in vivo $(29,30)$. AA, a widely used antioxidant, was revealed to delay the progression of age-associated diseases, which are highly susceptible to oxidative stress $(19,21)$. However, it is unknown whether AA can provide any resistance to oxidative stress for the protection of chondrocytes. The present study hypothesized that AA may confer protective effects against chondrocyte damage, which is induced by $\mathrm{H}_{2} \mathrm{O}_{2}$. By examining the apoptotic rate, viability and senescence of chondrocytes, AA was revealed to effectively reduce $\mathrm{H}_{2} \mathrm{O}_{2}$-induced damage by attenuating the increase of apoptosis, loss of viability and increase of senescence (Fig. 1 and 2). Graeser et al (23) reported that administering a single dose of AA (10-50 $\mu \mathrm{M})$ failed to protect chondrocytes from the damage induced by t-Butyl hydroperoxide. By contrast, Sharma et al (24) found that AA supplementation reduced the morphological and biochemical degeneration of chondrocytes in vivo. Notably, another previous report revealed that lower concentrations of AA did not protect against oxidative stress in retinal pigment epithelium cells until the concentration of AA reached $100 \mu \mathrm{M}$ (31). The present study surmised that any 
resistance to oxidative stress exerted by AA was likely to be associated with the concentration of AA.

Collagens and proteoglycans (in chondrocytes, Col2a1 and Agc1 are expressed) are the predominant constituents of the extracellular matrix, which are important in chondrocytes competing against various stress factors $(32,33)$. Previous studies confirmed that $\mathrm{H}_{2} \mathrm{O}_{2}$ reduces the level of proteoglycans in chondrocytes $(15,34,35)$. In the present study, the data supported that of previous studies by identifying that Col2al and Agc1 are, respectively, the major collagen and proteoglycan expressed by chondrocytes (Fig. 3A-B). In addition, the present results have also demonstrated that the administration of AA efficiently counteracts the inhibition of Col2al and Agc1 by $\mathrm{H}_{2} \mathrm{O}_{2}$ in $\mathrm{C} 28 / \mathrm{I} 2$ cells. In normal cartilage, the differentiation index is high as a result of the large quantity of Col2al and low quantity of Colla1 that are present. An augmented differentiation index is indicative of the active maintenance of the hyaline phenotype of chondrocytes $(36,37)$. By contrast, an upregulated expression of Colla1 or a decline in the differentiation index represented the formation of fibrocartilage rather than hyaline cartilage $(37,38)$. The present study revealed that $\mathrm{H}_{2} \mathrm{O}_{2}$ not only upregulated the expression of the Collal gene, but also inhibited the expression of Col2a1 (Figs. 3A, C and D). Furthermore, AA pretreatment inhibited the upregulation of the expression of the Colla1 gene and downregulation of $\mathrm{Col} 2 \mathrm{a} 1$ induced by $\mathrm{H}_{2} \mathrm{O}_{2}$ (Figs. 3A, C and D). Consequently, these findings demonstrated that AA not only stimulates the expression of collagens and proteoglycans, but also inhibits the differentiation of chondrocytes into fibrocartilage.

Several response transcription factors and signaling pathways, including MMP-3 (39), NF- $\mathrm{B}$ (13), the PKC/Nrf2 pathway (40) and the JNK/AP1 signaling pathway $(41,42)$, have been demonstrated to exert key effects on the protection against environmental and multiple cellular stresses in chondrocytes $(13,39-42)$. Theoretically, the specific regulation of these response transcription factors can cause various changes in pathologies and physiologies. Previous studies have identified the crosstalk between AA and MMP-3 in non-Hodgkin's lymphoma (43), the AA-mediated inhibition of NF- $\kappa$ B leading to the suppression of liver fibrosis (44), the regulatory role of $\mathrm{AA}$ in the $\mathrm{PKC} / \mathrm{Nrf} 2$ pathway (45) and a moderate AA-mediated attenuation of the elevated levels of the AP1 gene induced by $\mathrm{H}_{2} \mathrm{O}_{2}$ in the retinal pigment epithelium (31). These findings demonstrate that AA may affect multiple signaling pathways and that the regulatory mechanism in which AA is involved is highly dependent on the microenvironment. In order to identify the transcription factor(s), which AA modulates, four response transcription factors were selected, including MMP-3, NF- $\kappa \mathrm{B}$, the PKC/Nrf2 pathway and the JNK/AP1 signaling pathway. AA was revealed to repress the elevated transcriptional activities of the response transcription factors induced by $\mathrm{H}_{2} \mathrm{O}_{2}$, lowering them to basal activities (Fig. 4). This demonstrated that AA can regulate multiple factors and signaling pathways. These findings also revealed how promising novel therapeutic methods, which lack any substantial untoward effects due to the inhibition of any given transcription factors may be acquired.

Overall, the present study demonstrated that AA protected cultured chondrocytes from apoptosis, loss of viability and an increase in senescence under conditions of $\mathrm{H}_{2} \mathrm{O}_{2}$-induced oxidative stress in vitro. In addition, AA not only stimulated the expression of collagens and proteoglycans, but also inhibited the differentiation of chondrocytes in the presence of oxidative stress. The effects of AA were mediated by multiple regulatory pathways (or factors). Future studies will focus on improving the efficacy of AA for alleviating damage to chondrocytes induced by oxidative stress, and an investigation of AA pretreatment in vivo.

\section{Acknowledgements}

This study was funded by The Second Affiliated Hospital of Inner Mongolia Medical University.

\section{References}

1. Miyaki S and Asahara $\mathrm{H}$ : Macro view of microRNA function in osteoarthritis. Nat Rev Rheumatol 8: 543-552, 2012.

2. Triantafillou KM, Lauerman W and Kalantar SB: Degenerative disease of the cervical spine and its relationship to athletes. Clin Sports Med 31: 509-520, 2012.

3. Sun YQ, Zheng S, Yu J, Yan K and Tian W: Effect of total disc replacement on atypical symptoms associated with cervical spondylosis. Eur Spine J 22: 1553-1557, 2013.

4. Leong DJ, Li YH, Gu XI, et al: Physiological loading of joints prevents cartilage degradation through CITED2. FASEB J 25: 182-191, 2011.

5. Horton WE Jr, Bennion P and Yang L: Cellular, molecular, and matrix changes in cartilage during aging and osteoarthritis. J Musculoskelet Neuronal Interact 6: 379-381, 2006.

6. Chang Z, Huo L, Wu Y and Zhang P: HIF-1 $\alpha$ had pivotal effects on downregulation of miR-210 decreasing viability and inducing apoptosis in hypoxic chondrocytes. ScientificWorldJournal 2014: 876363,2014

7. Henrotin Y, Kurz B and Aigner T: Oxygen and reactive oxygen species in cartilage degradation: Friends or foes? Osteoarthritis Cartilage 13: 643-654, 2005.

8. Henrotin YE, Bruckner P and Pujol JP: The role of reactive oxygen species in homeostasis and degradation of cartilage. Osteoarthritis Cartilage 11: 747-755, 2003.

9. Ruiz-Romero C, Calamia V, Mateos J, Carreira V, Martínez-GomarizM,Fernández Mand Blanco FJ: Mitochondrial dysregulation of osteoarthritic human articular chondrocytes analyzed by proteomics: a decrease in mitochondrial superoxide dismutase points to a redox imbalance. Mol Cell Proteomics 8: 172-189, 2009.

10. Yu CJ, Ko CJ, Hsieh CH, Chien CT, Huang LH, Lee CW and Jiang CC: Proteomic analysis of osteoarthritic chondrocyte reveals the hyaluronic acid-regulated proteins involved in chondroprotective effect under oxidative stress. J Proteomics 99: 40-53, 2014.

11. Asada S, Fukuda K, Nishisaka F, Matsukawa M and Hamanisi C: Hydrogen peroxide induces apoptosis of chondrocytes; involvement of calcium ion and extracellular signal-regulated protein kinase. Inflamm Res 50: 19-23, 2001.

12. Ji JJ, Lin Y, Huang SS, Zhang HL, Diao YP and Li K: Quercetin: A potential natural drug for adjuvant treatment of rheumatoid arthritis. Afr J Tradit Complement Altern Med 10: 418-421, 2013.

13. Eo SH, Cho H and Kim SJ: Resveratrol Inhibits Nitric Oxide-Induced Apoptosis via the NF-Kappa B Pathway in Rabbit Articular Chondrocytes. Biomol Ther (Seoul) 21: 364-370, 2013.

14. Yoda M, Sakai T, Mitsuyama H, Hiraiwa H and Ishiguro N: Geranylgeranylacetone suppresses hydrogen peroxide-induced apoptosis of osteoarthritic chondrocytes. J Orthop Sci 16: 791-798, 2011.

15. Bhatti FU, Mehmood A, Wajid N, Rauf M, Khan SN and Riazuddin S: Vitamin E protects chondrocytes against hydrogen peroxide-induced oxidative stress in vitro. Inflamm Res 62: 781-789, 2013.

16. Henrotin Y and Kurz B: Antioxidant to treat osteoarthritis: Dream or reality? Curr Drug Targets 8: 347-357, 2007.

17. Chambial S, Dwivedi S, Shukla KK, John PJ and Sharma P: Vitamin $\mathrm{C}$ in disease prevention and cure: An overview. Indian J Clin Biochem 28: 314-328, 2013. 
18. Heo JH, Hyon L and Lee KM: The possible role of antioxidant vitamin $C$ in Alzheimer's disease treatment and prevention. Am J Alzheimers Dis Other Demen 28: 120-125, 2013.

19. Özkaya D, Naziroğlu M, Armağan A, Demirel A, Köroglu BK, Colakoğlu N, Kükner A and Sönmez TT: Dietary vitamin C and $\mathrm{E}$ modulates oxidative stress induced-kidney and lens injury in diabetic aged male rats through modulating glucose homeostasis and antioxidant systems. Cell Biochem Funct 29: 287-293, 2011.

20. Naziroğlu M, Butterworth PJ and Sonmez TT: Dietary vitamin C and $\mathrm{E}$ modulates antioxidant levels in blood, brain, liver, muscle, and testes in diabetic aged rats. Int J Vitam Nutr Res 81: 347-357, 2011.

21. Omata S, Sonokawa S, Sawae Y and Murakami T: Effects of both vitamin $\mathrm{C}$ and mechanical stimulation on improving the mechanical characteristics of regenerated cartilage. Biochem Biophys Res Commun 424: 724-729, 2012.

22. Braconi D, Laschi M, Taylor AM, Bernardini G, Spreafico A, Tinti L, Gallagher JA and Santucci A: Proteomic and redox-proteomic evaluation of homogentisic acid and ascorbic acid effects on human articular chondrocytes. J Cell Biochem 111: 922-932, 2010

23. Graeser AC, Giller K, Wiegand H, Barella L, Boesch SaadatmandiC and Rimbach G: Synergistic chondroprotective effect of alpha-tocopherol, PCR, and selenium as well as glucosamine and chondroitin on oxidant induced cell death and inhibition of matrix metalloproteinase-3--studies in cultured chondrocytes. Molecules 15: 27-39, 2010.

24. Sharma G, Saxena RK and Mishra P: Regeneration of static-load-degenerated articular cartilage extracellular matrix by vitamin C supplementation. Cell Tissue Res 334: 111-120, 2008

25. Coppé JP, Desprez PY, Krtolica A and Campisi J: The senescence-associated secretory phenotype: The dark side of tumor suppression. Annu Rev Pathol 5: 99-118, 2010.

26. Philipot D, Guérit D, Platano D, Chuchana P, Olivotto E, Espinoza F, Dorandeu A, Pers YM, Piette J, Borzi RM, et al p16INK4a and its regulator miR-24 link senescence and chondrocyte terminal differentiation-associated matrix remodeling in osteoarthritis. Arthritis Res Ther 16: R58, 2014.

27. Desando G, Cavallo C, Tschon M, Giavaresi G, Martini L, Fini M, Giardino R, Facchini A and Grigolo B: Early-term effect of adult chondrocyte transplantation in an osteoarthritis anima model. Tissue Eng Part A 18: 1617-1627, 2012.

28. Mirza R, Qiao S, Tateyama K, Miyamoto T, Xiuli L and Seo H: $3 \beta$-Hydroxysterol-Delta24 reductase plays an important role in long bone growth by protecting chondrocytes from reactive oxygen species. J Bone Miner Metab 30: 144-153, 2012

29. Henrotin Y, Clutterbuck AL, Allaway D, Lodwig EM, Harris P, Mathy-Hartert M, Shakibaei M and Mobasheri A: Biological actions of curcumin on articular chondroc\$ytes. Osteoarthritis Cartilage 18: 141-149, 2010.

30. Lim HD, Kim YS, Ko SH, Yoon IJ, Cho SG, Chun YH, Choi BJ and Kim EC: Cytoprotective and anti-inflammatory effects of melatonin in hydrogen peroxide-stimulated CHON-001 human chondrocyte cell line and rabbit model of osteoarthritis via the SIRT1 pathway. J Pineal Res 53: 225-237, 2012.

31. Yin J, Thomas F, Lang JC and Chaum E: Modulation of oxidative stress responses in the human retinal pigment epithelium following treatment with vitamin C. J Cell Physiol 226 2025-2032, 2011.
32. Bhosale AM and Richardson JB: Articular cartilage: Structure, injuries and review of management. Br Med Bull 87: 77-95, 2008.

33. Nugent AE, McBurney DL and Horton WE Jr: The presence of extracellular matrix alters the chondrocyte response to endoplasmic reticulum stress. J Cell Biochem 112: 1118-1129, 2011.

34. Jallali N, Ridha H, Thrasivoulou C, Underwood C, Butler PE and Cowen T: Vulnerability to ROS-induced cell death in ageing articular cartilage: The role of antioxidant enzyme activity. Osteoarthritis Cartilage 13: 614-622, 2005.

35. Tiku ML, Gupta S and Deshmukh DR: Aggrecan degradation in chondrocytes is mediated by reactive oxygen species and protected by antioxidants. Free Radic Res 30: 395-405, 1999.

36. Marlovits S, Hombauer M, Truppe M, Vècsei V and Schlegel W: Changes in the ratio of type-I and type-II collagen expression during monolayer culture of human chondrocytes. J Bone Joint Surg Br 86: 286-295, 2004.

37. Diaz-Romero J, Nesic D, Grogan SP, Heini P and Mainil-Varlet P: Immunophenotypic changes of human articular chondrocytes during monolayer culture reflect bona fide dedifferentiation rather than amplification of progenitor cells. J Cell Physiol 214: 75-83, 2008.

38. Aini H, Ochi H, Iwata M, Okawa A, Koga D, Okazaki M, Sano A and Asou Y: Procyanidin B3 prevents articular cartilage degeneration and heterotopic cartilage formation in a mouse surgical osteoarthritis model. PLoS One 7: e37728, 2012.

39. de Seny D, Cobraiville G, Charlier E, Neuville S, Esser N, Malaise D, Malaise O, Calvo FQ, Relic B and Malaise MG: Acute-phase serum amyloid a in osteoarthritis: Regulatory mechanism and proinflammatory properties. PLoS One 8: e66769, 2013

40. Wruck CJ, Fragoulis A, Gurzynski A, Brandenburg LO, Kan YW, Chan K, Hassenpflug J, Freitag-Wolf S, Varoga D, Lippross S, et al: Role of oxidative stress in rheumatoid arthritis: Insights from the Nrf2-knockout mice. Ann Rheum Dis 70: 844-850, 2011.

41. Karreth F, Hoebertz A, Scheuch H, Eferl R and Wagner EF: The AP1 transcription factor Fra2 is required for efficient cartilage development. Development 131: 5717-5725, 2004

42. Hiyama A, Gogate SS, Gajghate S, Mochida J, Shapiro IM and Risbud MV: BMP-2 and TGF-beta stimulate expression of beta1,3-glucuronosyl transferase 1 (GlcAT-1) in nucleus pulposus cells through AP1, TonEBP, and Sp1: Role of MAPKs. J Bone Miner Res 25: 1179-1190, 2010.

43. Skibola CF, Bracci PM, Halperin E, Nieters A, Hubbard A, Paynter RA, Skibola DR, Agana L, Becker N, Tressler P, et al: Polymorphisms in the estrogen receptor 1 and vitamin $\mathrm{C}$ and matrix metalloproteinase gene families are associated with susceptibility to lymphoma. PLoS One 3: e2816, 2008.

44. Abhilash PA, Harikrishnan R and Indira M: Ascorbic acid suppresses endotoxemia and NF- $\mathrm{NB}$ signaling cascade in alcoholic liver fibrosis in guinea pigs: A mechanistic approach. Toxicol Appl Pharmacol 274: 215-224, 2014.

45. Jin M, Kumar A and Kumar S: Ethanol-mediated regulation of cytochrome P450 2A6 expression in monocytes: Role of oxidative stress-mediated PKC/MEK/Nrf2 pathway. PLoS One 7: e35505, 2012. 